Meta

Journal des traducteurs

Translators' Journal

\title{
Translation Between Unrelated Languages and Cultures, as Illustrated by Japanese-English Translation
}

\section{Judy Wakabayashi}

Volume 36, numéro 2-3, juin 1991

URI : https://id.erudit.org/iderudit/004585ar

Aller au sommaire du numéro

\section{Éditeur(s)}

Les Presses de l'Université de Montréal

ISSN

0026-0452 (imprimé)

1492-1421 (numérique)

Découvrir la revue

Citer cet article

Wakabayashi, J. (1991). Translation Between Unrelated Languages and Cultures, as Illustrated by Japanese-English Translation. Meta, 36(2-3), 414-423.

\section{Résumé de l'article}

La plupart des écrits sur la traduction s'appuient sur les langues indo-europeennes, qui sont non seulement liées par des facteurs linguistiques, mais ont aussi des racines culturelles semblables. Pour contrecarrer cette tendance eurocentrique, on abordera certains aspects de la traduction japonais-anglais en mettant I'accent surtout sur les différences de structure des paragraphes et du discours et sur les facteurs culturels. Le but n'est pas de demontrer que la typologie linguistique et l'ecart socioculturel entrent en ligne de compte dans la theorie et la pratique de la traduction. Afin d'éviter de ne pas etre compris, le traducteur de langues sans lien entre elles, utilisées dans divers contextes de communication, doit alter au-delà de ce qui est habituellement consideré comme son rôle pour se rapprocher de celui d'un éditeur. La traduction de systèmes ethnolinguistiquement divergents peut contribuer a des études de traduction en cernant les problemes qui sont moins évidents ailleurs. 


\title{
TRANSLATION BETWEEN UNRELATED LANGUAGES AND CULTURES, AS ILLUSTRATED BY JAPANESE-ENGLISH TRANSLATION
}

\author{
JUDY WAKABAYASHI \\ Department of Japanese and Chinese Studies, \\ University of Queensland, Australia
}

RÉSUMÉ

La plupart des écrits sur la traduction s'appuient sur les langues indoeuropéennes, qui sont non seulement liées par des facteurs linguistiques, mais ont aussi des racines culturelles semblables. Pour contrecarrer cette tendance eurocentrique, on abordera certains aspects de la traduction japonais-anglais en mettant l'accent surtout sur les différences de structure des paragraphes et du discours et sur les facteurs culturels. Le but n'est pas de démontrer que la typologie linguistique et l'écart socioculturel entrent en ligne de compte dans la théorie et la pratique de la traduction. Afin d'éviter de ne pas être compris, le traducteur de langues sans lien entre elles, utilisées dans divers contextes de communication, doit aller au-delà de ce qui est habituellement considéré comme son rôle pour se rapprocher de celui d'un éditeur. La traduction de systèmes ethnolinguistiquement divergents peut contribuer à des études de traduction en cernant les problèmes qui sont moins évidents ailleurs.

ABSTRACT

Most writing on translation is based on Indo-European languages, which are not only linguistically related but also share a similar cultural background. In an attempt to counter this eurocentric bias, we shall discuss some aspects of Japanese-English translation, focussing especially on differences in paragraph and discourse structure and on cultural factors. The aim is to demonstrate that linguistic typology and sociocultural distance need to be taken into account in translation theory and practice. We conclude that in order to avoid misunderstanding, at times the translator of unrelated languages used in different communicative frameworks may have to step beyond what is normally regarded as the role of the translator into a role approaching that of an editor. Translation between ethnolinguistically divergent systems may contribute to translation studies by highlighting problem areas that are less evident elsewhere.

\section{INTRODUCTION}

Most $^{1}$ writing on translation has been based on translation between languages of the Indo-European family, which not only share many lexical and morphosyntactic features, with considerable etymological and phonological similarity, but also have similar cultural backgrounds. The linguistic and cultural differences are relatively minor in comparison to the differences between typologically diverse languages used in cultures that have little in common historically, geographically, socially or politically.

The Indo-European language family is only one of seventeen major language groups throughout the world ${ }^{2}$, and the fact that the literature on translation is based largely on 
this one language family has led to a eurocentric bias in translation studies. In an attempt to broaden the basis of discussion, we shall present some data from Japanese, a non-IndoEuropean language used in a non-Western culture. Though there is debate over to which language group Japanese belongs - some scholars claim that it is unrelated to any other language, some maintain that it is a subgroup of the Altaic family, and others note similarities with Malayo-Polynesian languages - the fact remains that genetically it is quite unrelated to Indo-European languages.

If translation theory is universally applicable and the type and frequency of translation problems, procedures and strategies are the same in all language pairs, this eurocentric bias in translation studies is of no import. Seleskovitch, for example, takes this view, arguing that the unrelatedness of languages presents no special difficulty in transllation and is of no consequence in translation theory. Once the sense of the source text has been grasped, it can be readily expressed in any language "regardless of the words used in the original language" (Seleskovitch 1977: 28).

The consensus of opinion among writers on Japanese-English (J-E) translation, however, seems to be that translation between languages that are linguistically and culturally distant does differ from translation between related languages, both qualitatively and in the degree of difficulty. Kano (1979: 6) observes that

Those who have worked only among European languages may find it difficult to appreciate the obstacles posed when stepping outside the common backyard of the Indo-European language group and being confronted with a completely different set of grammatical, philosophical and verbal assumptions. They demand a different type of transfer when being translated, including the structure of the logic, vocabulary that a dictionary may not provide, substitution of expressions, and even rearranging whole blocks of material to provide coherence for the mind that has been trained to think in English.

This view is supported by Seidensticker (1979: 71-72), who states that the difficulty of translating Japanese into a European language

is greater by a considerable degree than is to be accounted for by the greater difficulty of the languages themselves.

He attributes this to the fact that English and Japanese are used in such different cultures. Elsewhere (1983: 31 ) he expresses the view that there is a reduced possibility of perfect translation between unrelated languages. In a similar vein, Kono (1975: 163) claims that the loss of fine nuances is greater in translation between linguistically and geographically ${ }^{3}$ distant languages than between languages which lie close together geographically and on the linguistic spectrum. Others have pointed out that the similarities between related languages make literal translation far more possible (though not necessarily desirable) than in the case of unrelated languages.

Here we shall examine this issue of whether or not the degree of linguistic relatedness is of any importance in translation theory and practice, and we shall look also at the relevance of the degree of sociocultural distance, using examples from Japanese-English translation to illustrate our argument.

\section{JAPANESE-ENGLISH TRANSLATION}

The lexical, grammatical and stylistic ${ }^{4}$ characteristics of Japanese will not be discussed here because of space limitations and because they are adequately documented elsewhere. Here we shall focus on some suprasentential features of Japanese texts and some of the cultural constraints at work in J-E translation, because these are areas that can make a particular contribution to general translation studies by highlighting problem 
areas that are less apparent in translation between related languages with a common cultural background.

\section{(a) Paragraph structure}

The concept of a paragraph as a thematic unit is not as firmly rooted in Japan as in the West, and so the decision as to where to start a new paragraph is often largely arbitrary. Moreover, whereas English paragraphs are generally constructed around a topic sentence, which usually takes initial position, Japanese paragraphs often have no topic sentence at all. Or if one does exist, it may be set apart in a paragraph by itself as an introduction to the following paragraph, or it may occur at the end of the paragraph. Furthermore, there is a tendency to summarize when closing a paragraph, with the result that related items are often found at the beginning and the end of a paragraph. One form that this may take is the following: assertion, rhetorical question, reasons for assertion, repetition of assertion (Terry 1985: 3). Another common pattern is that whereby the final sentence of a paragraph commences a new theme, which is then taken up again at the start of the following paragraph in a kind of textual chain. Again, two antithetical statements may be placed next to each other to give a balanced presentation. This is appreciated as a mark of style in Japanese, as are logical "gaps" or leaps between paragraphs, but may confuse the English reader, who expects continuity and logical development. Whereas English readers anticipate that changes in direction will be signaled by transition statements, in Japanese these may be absent or attenuated, and it is up to the reader to determine the intended relationships (Hinds 1987: 146).

The translator must decide whether or not the way in which the Japanese text is divided into paragraphs is justified. If the breaks are purely arbitrary, as is often the case, then it is permissible and advisable to reorganize the formal paragraph divisions into paragraphs with conceptual unity, as long as the changes are not detrimental to the meaning or the emphasis. Likewise, if reproducing the internal structure of the paragraphs would result in a rhetorical pattern which is alien to the reader of English and which might hamper understanding, the translator of informative texts ${ }^{5}$ should not hesitate to reorganize the order of presentation.

\section{(b) Discourse organization}

As with the organization of paragraphs, the manner in which different languages or societies structure discourses is not universal, but follows what Loveday (1986: 116) calls "socioculturally established conventions."

Although there are areas of overlap in Japanese and English rhetorical strategies e.g. the pattern of introduction-main body-conclusion is similar to the most common English pattern, and scientific writing in Japanese resembles the structure of English (and international) scientific writing (see Sugimoto 1978) - there are also certain distinctive ways in which information is organized in Japanese discourses. Moreover, though the same rhetorical patterns may exist in both languages, the frequency of usage may differ - i.e. these are not necessarily culture-specific strategies of organization, but culturallypreferred strategies, as has been pointed out by Burtoff (1983).

One traditional Japanese strategy, known as kishootenketsu, is that whereby the introduction $(\mathrm{ki})$ is followed by a development of the argument (shoo), as in English, but then a change of focus (ten) occurs whereby one or more peripherally-related subthemes are introduced before the conclusion (ketsu). This pattern, which is common in essays, can confuse the English reader, as the digressions (ten) may have little direct connection with the main thread of argument. Another characteristic pattern is what Hinds (1984) refers to as the "return to baseline theme" pattern, whereby the writer restates the main theme in each paragraph before progressing to a different perspective. 
Whereas the English writer tends to make a statement or generalization and then justify it, the Japanese writer is more likely to enumerate various reasons before stating the conclusion (or simply leaving it up to the reader to infer the intended conclusion). That is, causal chains are likely to be followed by a final generalization (inductive reasoning), rather than an initial generalization being then substantiated by various reasons (deductive reasoning). Toyama (1977) has likened the structure of Japanese texts to a triangle, with the important information coming toward the end, and that of Western texts to an inverted triangle, with significant information coming in the early part. Other writers have pointed out that the linear development which is the norm in English discourse is in contrast to the circular pattern of exposition common in Oriental writing. There is also a distinct preference in Japanese for presenting information in a chronological order, whereas the English writer is more likely to order information according to a hierarchy of importance.

Opening and concluding paragraphs also exhibit certain crosscultural differences. Though Nishimura (1986) found few significant differences between Japanese and English openings, Endo (1988: 6) notes that in order to avoid an abrupt-sounding opening in the English, the translator may need to fill out the introductory paragraph by adding a

... very broad statement that rephrases the content of the first sentence of the Japanese, then links it to that more specific sentence by repetition... .

The differences between Japanese and English conclusions are more striking. The writer of English is taught that a conclusion should emphasize and summarize the main points, evaluate what has been presented and avoid trailing off into vague generalities i.e. a strong finish is required. In Japanese, however, the conclusion is not necessarily conclusive. There is a preference for ending with a generalization, or for simply indicating a doubt or raising a question. Brown (1987: 36) writes that

... the Oriental tradition favors a process by which elaborate stage-setting precedes the focal message and where the listener is guided through the reasoning process and the conclusion more or less allowed to unobtrusively emerge.

A desire to avoid possible disagreement may underlie this tendency not to make a point or to commit oneself, which is achieved by presenting a range of differing viewpoints. Loveday (1986: 116) notes that

Westerners often view such a format as devoid of any particular message, and see the speaker/writer as 'shallow'. The [Japanese], in turn, consider the 'forcing' of a conclusion on the listener/reader to be quite unsophisticated and inelegantly simplistic.

Much of what has been written about the rhetorical structure of Japanese texts is conflicting and fragmentary. Moreover, the question remains of the frequency of these distinctively Japanese patterns relative to that of patterns which accord with English usage. Without further research, all the translator can do is to be aware of such differences and to feel free to make adjustments to the text organization if necessary in order to avoid conveying an incorrect impression, which is what may happen if the structure of the original text is retained. This question of discourse organization is of more than purely academic interest. If cultural expectations as to the organization of paragraphs and the discourse as a whole or as to openings and conclusions are not met, the reader may miss the point. The degree of familiarity with the structure of a discourse has an identifiable influence on comprehension. Studies by Hinds (1984) and Urquhart (1984), for example, have shown that a relationship also exists between discourse organization and the retention or recall of information. Hence there is a need to conform to the norms and 
communicative conventions of the target language, though naturally the semantic content must remain invariant.

Just as the translator has little hesitation in altering the word order in a source language sentence so as to conform with target language requirements, likewise there is no reason why changes should not be carried out at the suprasentential level when necessary to achieve dynamic equivalence. The translator may need to change the superstructural sequencing so as to retain the impact or preserve the correct emphasis; so that the reader does not feel s/he is missing the point; so as not to sound anti-climactic; so as to clarify the link with preceding material and to make the text flow better; or so as to improve readability. Failure to make these changes may impose an unnecessary strain on the reader.

Newmark has criticized the recent trend toward regarding the whole text as the unit of translation, saying that discourse analysis is only a "marginal aspect of translation theory" (1981: 32). Though crosscultural differences in paragraph and discourse structure may not be a factor in every translation, they do seem to occur frequently in J-E translation. As Newmark is basing his remarks solely on Indo-European languages, we feel that he underestimates the contribution that may be made by contrastive textology to translation studies.

\section{(c) Cultural factors}

Discussions in the translation literature of the West about the role of cultural factors in non-literary translation rarely go beyond the lexical level (i.e. semantic skewing and lexical gaps), despite the fact that more fundamental differences in values and thought patterns can have considerable effect on the reception of a translation ${ }^{6}$. By contrast, this topic is a common subject of discussion in Japanese writing on translation.

The neglect of this deeper level of attitudinal differences is probably due to the fact that translators dealing with Indo-European languages are working within the comparatively homogeneous framework of Western logic, and so the differences arising in translation are minimal. As Brown (1987: 35) has pointed out, however, logic is not "invariant across cultures".

An utterance may seem illogical because the author's logic really is faulty, because the statement does not accurately reflect the intended meaning, or because the author may expect the reader to draw the necessary inferences. In translation, another possibility is that though the utterance is logical within the framework of the source language and culture, it runs contrary to the expectations of foreign readers. Lederer (1976: 17) goes so far as to claim that more frequently than infractions of the normative rules of a language, it is violations of the intrinsic logic of the target language that lead to obscurity in translation. Japanese-English translation is an excellent illustration of this.

In the past many Japanese and Western writers 7 , including some renowned Japanese linguists, have bemoaned the "illogicality" or inferiority of the Japanese language. They have claimed that European languages are better suited to expressing scientific thought or logical, analytical ideas involving deductive reasoning than the Japanese language, which is more suited to describing emotions. Some of the specific causes to which this alleged illogicality of the Japanese language has been variously attributed are the following: its lexical and structural ambiguity; the fact that the language is verb-based and hence less "suited" to hard logic than noun-based languages such as English; the fact that the verb comes at the end of the sentence; the fact that the distinction between assertion and supposition does not have to be made explicit in Japanese; the fact that often the predicate of a sentence does not match the subject or topic; the fact that the subject is often not stated explicitly; the fact that different categories can be mixed and juxtaposed; the fact that modifying words are frequently far removed from their referents; 
the different use of causal relations to that in English; and the fact that skewing often exists between the functional or logical relations expressed by the linguistic structures and the actual relationships. In addition, certain stylistic characteristics of Japanese are at variance with the ideals of good English usage - e.g. the emphasis on phatic language, the tolerance for repetitiousness and verbosity, and the high frequency of vague and selfeffacing expressions, hyperbole and rhetorical questions (Wakabayashi 1990).

The Japanese language, however, is a perfectly adequate vehicle for expressing Japanese thought, and the high level of technology in Japan refutes the suggestion that the language is inherently incapable of expressing scientific ideas. These writers are confusing the language with the manner in which it is used. It is important to stress this point that it is not the language that is "illogical", but simply how it is often used. In translation, this is compounded by the fact that attitudes toward language use in Japan differ considerably from those in the West.

Toyama (1977: 3) claims that in Japan justifying one's actions in explicit, logical terms is regarded as "sissy" or apologetic. If explanation is unavoidable, it should be kept as short as possible. Rather than explain in full, it is considered preferable to allow the reader to infer the intended meaning. The result is that much is simply implied, without appearing on the surface structure. Another aspect of language attitudes in Japan is a belief in the superiority of instinct or intuition over logic. This emphasis on the emotional aspect has traditionally been regarded as more aesthetically appealing and in line with the mores of Japanese society than is hard, cold Western logic.

These differences have led Toyama (1988: 8) to characterize Western logic as linear and Japanese logic as "stippled". This term ${ }^{8}$ refers to a situation in which elements that are understood by the participants because of their shared background knowledge or contextual knowledge are omitted, resulting in "gaps" in the logical progression. Hinds (1986: 26) comments that in Japanese minimal verbal clues are supplied, whereas English speakers require maximum verbal clues. Elsewhere (1987: 143) he writes that whereas in English the writer is primarily responsible for effective communication, in Japanese the burden rests with the reader, and says that in a reader-responsible language there is greater tolerance for ambiguity and imprecision.

Some of the main differences that are alleged to exist between Japanese and Western thought patterns (usually represented by English) can be summarized as follows:

\begin{tabular}{|l|l|}
\hline \multicolumn{1}{|c|}{ Japanese } & \multicolumn{1}{c|}{ English } \\
\hline Subjective & Objective \\
Concrete & Abstract \\
Appeals to emotions, senses & Appeals to logic \\
Hearer-oriented & Speaker-oriented \\
Focus on situation & Focus on entities/people \\
Highly dependent on & Dependent on linguistic \\
situational context & context \\
Circular/circumlocutionary & Direct \\
Stippled & Linear \\
Negative & Positive \\
Derived from Buddhist/ & Derived from Greek philosophy \\
Confucian philosophical traditions & \\
\hline
\end{tabular}


Though there is nothing inhe rently superior in Western thought or logic, and it would be easy to cite examples of illogicalities in English and how it is used ${ }^{9}$, the point is that attitudes toward logic and language use in English-speaking Western nations do differ markedly from those in Japanese society. We are not making any value judgments here on either the Japanese language or its users, but simply pointing out these differences in communicative strategy and the fact that they must be taken into account when translating. As Miller (1986: 111) says, the question is how much of the Japanese structure can reasonably be imposed on the English reader. If transferred holus-bolus, the translation may appear "fragmented, truncated, abbreviated, vague, and oblique ..." to the English reader (Brown 1987: 33-4). This can result in a communication breakdown, as well as negative stereotyping because of a lack of awareness of these culture-dependent differences.

DISCUSSION

The linguistically- and culturally-determined differences between the Japanese and English languages and how they are used lend support to the claim that translation involving heterogeneous ethnolinguistic systems differs in certain respects from translation between related languages belonging to the same cultural sphere, and that the degree of translational difficulty is also greater. In an article on translation between typologically diverse languages, focusing especially on J-E translation, Philippi (1989) concludes that

... if translators working between typologically diverse languages can successfully demonstrate that linguistic typology is a matter of decisive importance in translation theory, this will inevitably lead to a general recognition of the fact that such translations are more difficult to accomplish, and therefore deserve greater rewards, than translations between typologically similar languages.

We would take this comment a step further to state that not only linguistic unrelatedness, but also the degree of cultural overlap, is an important factor in translation theory and practice.

Some writers, however, have looked at this issue of unrelatedness from another angle. Seleskovitch views linguistic similarity as a greater obstacle to translation than unrelatedness, because, she claims, the translator is more likely to become hypnotized by formal resemblances. She asserts (1984: 134) that it is easier for the translator working from a related language to get away with poor translation because the similarity of form enables adequate comprehension, and that the very structures of unrelated languages force the translator to take sense as the guide in order to avoid ending up with an awkward translation. A similar line is taken by a Toyota Foundation report (1986: 30), which says that when translating from Japanese

Paradoxically, ... the very imposssibility of literal translation frees the translator to select the form of expression he or she considers most appropriate to the spirit of the original.

However, these claims are unsubstantiated, and actual translations from Japanese, especially ones by inexperienced translators, often demonstrate a close adherence to the form of the original insofar as obligatory grammatical transformations permit. Moreover, with unrelated languages the frequent impossibility of straight conversion from source language lexis and structure to the target language equivalents places far greater demands on the translator's ability to analyse and interpret the source text and to reexpress it in good English.

How much liberty may the translator take in adjusting the SLT to the needs and expectations of TLT readers? Is it the task of the translator to make implicit elements 
explicit and to reorder the structure for ease of comprehension, for example, or does such "censorship" lie only within the province of the editor? From the viewpoint of translators used to working with typologically similar languages used in related cultures, the J-E translator may appear at times to step beyond the bounds of translation into the realm of editing or rewriting. Rearranging the order of sentences in a paragraph or paragraphs within a discourse, and tightening or adjusting the logic so that it does not mislead the English reader may seem to constitute adaptation. For instance, House (1982: 200) says that a translation that makes unwarranted adjustments to the expectations of the target culture is not a translation, but a covert version, and that the application of a "cultural filter" is unjustified. The keyword here is "unwarranted". In informative texts, naturalness in the TLT is a valid criterion, and certain changes are not only "warranted" but essential so as not to hinder communication of the message. As McClellan (1964: 20) notes, the translator of unrelated languages has "necessary freedom" which

... may very well bring about a blurring of the distinction between translation and original writing. [...]

When the languages are so very different, when the cultural contexts also are very different, and, finally, when literary standards are really much further apart than we sometimes like to admit, perhaps the translator must have the kind of freedom of expression which, though purporting to be translation, amounts in fact to explanation.

This viewpoint is supported by Ellingworth (1987: 53), who writes that

The translator needs to become aware of elements which, though entirely secondary in the original text, risk attracting disproportionate emphasis in translation, because they conflict with the modern reader's cultural expectations. Some degree of de-emphasis may be in order in such cases. This is in fact the reverse of transculturation: it is an attempt to preserve equivalence of meaning across a cultural gap.

Failure to intervene may result in undertranslation, overtranslation or mistranslation. Miller (1988a: 31-2) asserts that the problem of "robbing" the original - "rendering it into something that is less than it really is" (i.e. omitting elements) is more of a problem between related languages. He says that with unrelated languages the problem is rather one of supererogation - adding elements that were not in the original text. However, I disagree with this claim. Though non-intervention may result in undertranslation in certain areas of J-E translation (e.g. failure to make explicit the implicit subject, to add the appropriate articles or to distinguish between singular and plural), these areas are mainly ones in which the grammatical requirements of English force the translator to add such information, so in reality there is little likelihood of undertranslation. More likely is the risk of overtranslation (as distinct from supererogation), whereby the translator "faithfully" reproduces all of the redundancies, repetition, verboseness, vague sentence endings, and connectives of Japanese. As stylistic options rather than compulsory elements, these are more liable to result in overtranslation.

Though this emphasis on the requirements of the target language and culture may be regarded as a normative viewpoint, we believe that this is justified in the translation of informative texts. In literature, of course, it may be these very differences that make the source text worth translating, so as to introduce target language readers to a new world.

Although we have emphasized cultural and linguistic differences here, we do not subscribe to Kipling's "East is East and West is West, and never the twain shall meet" school of thought. Reconciling these two differing systems is the challenge and achievement of the translator. Nor should our remarks be interpreted as support for the theme of ethnolinguistic separatism found in much Japanese writing, with its 
... ethnocentric notions that proclaim the uniqueness and superiority of the Japanese language, its inexpressability, untranslatibility [sic] and unlearnability by non-Japanese as well as its extraordinary spiritual power ... (Loveday 1986: 19).

The low level of linguistic and cultural similarity between Japanese and English reduces the degree of automation in translation and brings problems to the fore. Hence a study of $\mathrm{J}$-E translation may contribute to translation theory in general by highlighting processes, procedures and strategies that are automatized in other language pairs and are less accessible for study. As a representative of translation between ethnolinguistically divergent systems, Japanese-English translation can help extend the boundaries of translation theory and practice to reveal some areas that tend to be overlooked in translation between Indo-European languages.

\section{NOTES}

1. The major exception in the literature is the writings of Nida and other Bible translators, who have extensive experience with numerous African and Amerindian languages. In this case, though, the translators have been translating from one foreign language (Greek or Hebrew) into another foreign language, and the spiritual aspects involved in Bible translating give an added dimension to their work that is not present in other types of translation.

2. In addition there are "language isolates", pidgin and Creole languages, and invented languages such as Esperanto.

3. Improved communications nowadays, however, mean that geographical distance is less of a factor than, say, 100 years ago. Moreover, there are instances of linguistically unrelated languages existing in close geographical proximity - e.g. Australian Aboriginal languages and Amerindian languages spoken alongside English. Interaction between languages and cultures is also increasing. The English language has had a considerable influence on Japanese in the past century, just as Western culture has had an enormous impact on Japan.

4. For a discussion of the stylistic aspects, see Wakabayashi (1990).

5. Our discussion here is confined to the translation of non literary texts.

\section{BIBLIOGRAPHY}

BROWN, R.A. (1987): "Contextual Inference in Japanese and English", Asian and Pacific Quarterly of Cultural and Social Affairs, vol. XIX, 1, 32-39.

BURTOFF, M.J. (1983): "The Logical Organization of Written Expository Discourse in English: A Comparative Study of Japanese, Arabic, and Native Speaker Strategies", (ESL) Ph.D., Georgetown University.

ELLINGWORTH, P. (1987): "Translating the Bible inclusively", Meta, 32-1, pp. 46-54.

ENDO, R. (1988): "Japanese to English", Asahi Evening News, 2/7/88, 6.

GALTUNG, J. and F. NISHIMURA (1983): "Structure, Culture and Languages: an Essay Comparing the IndoEuropean, Chinese and Japanese Languages", Social Science Information 22, 6, pp, 895-925.

GILE, D. (1985) : «La logique du Japonais et la traduction des textes non litteraires: une presentation du problème», Babel XXI/2, pp. 86-94.

GILE, D. (1987): "An Overview of the Characteristics of Translation from Japanese into Western Languages", JAT Bulletin 29, pp. 7-9.

HINDS, J. (1984): "Retention of Information Using a Japanese Style of Presentation", Studies in Language 8, 1 , pp. $46-69$

HINDS, J. (1986): Situation vs. Person Focus: Nihongo rashisa to eigo rashisa, Kuroshio Shuppan, Tokyo.

HINDS, J. (1987): "Reader Versus Writer Responsibility: a New Typology", U. Connor and R. Kaplan (Eds.), Writing Across Languages: Analysis of L2 Text, Reading, Mass., Addison Wesley, pp. 141-152.

HOUSE, J. (1982): A Model for Translation Quality Assessment, Tübingen, Gunter Narr.

KANO, T. (1979): The Alchemist: Philosophy and Problems in Japanese-English Translation, Translation Service Center Newsletter, 1, pp. 5-7.

KONO, I. (1975): Honyaku jootatsuhoo, Koodansha Gendai Shinsho, Tokyo.

LEDERER, M. (1976) : Synecdoque et traduction, Études de linguistique appliquée 24, pp. 13-41.

LOVEDAY, L.J. (1986): Explorations in Japanese Sociolinguistics, John Benjamins Publishing Company, Amsterdam/Philadelphia.

McCLELLAN, E. (1964): Translation as Implicit Commentary, Journal of the Association of Japanese Teachers, vol. II, 1-2, pp. 18-20. 
McQUEEN, I.L. (1986): Nihonjin wa, tekunikaru raitaa ni nareru no ka, The Technical Writer, vol. 3, pp. 76-77.

MILLER, R.A. (1986): Nihongo: In Defence of Japanese, The Athlone Press, London.

MILLER, R.A. (1988a): Linguistics and Japanese Translation, Asian \& Pacific Quarterly of Cultural and Social Affairs, vol. XX, no. 2, Cum. no. 62, pp. 2-36.

MILLER, R.A. (1988b): Logic and Language: the Case of Japanese, Asian and Pacific Quarterly of Cultural and Social Affairs, vol. XX, no. 1, pp. 1-20.

NEWMARK, P. (1981): Approaches to Translation, Pergamon Press, Oxford.

NISHIMURA, Y.K. (1986): Prose-organizing Strategies of Japanese College Students: a Contrastive Analysis, Descriptive and Applied Linguistics, vol. 19, pp. 207-218.

OIDE, A. (1965): Nihongo to ronri, Koodansha Gendai Shinsho, Tokyo.

PHILIPPI, D. (1989): "Translation Between Typologically Diverse Languages", pre-publication version of paper subsequently published in abbreviated form in Meta, 34-4, pp. 680-685.

SEIDENSTICKER, E.G. (1979): This Country, Japan, Kodansha International Ltd., Tokyo.

SEIDENSTICKER, E.G. (1983): Chiefly on Translating the Genji, The Journal of Japanese Studies, vol. 6-1, pp. 15-47.

SELESKOVITCH, D. (1977): Why Interpreting is not Tantamount to Translating Languages, (Threldford Memorial Lecture 1977), The Incorporated Linguist, vol. 16-2, London, pp. 27-33.

SELESKOVITCH, D. (1984) : «Les niveaux de traduction», D. Seleskovitch and M. Lederer : Interpréter pour traduire, Paris, Didier Érudition.

SUGIMOTO, E. (1978): "Contrastive Analysis of English and Japanese Technical Rhetoric", M. Todd Trimble et al. (Eds.), English for specific purposes. science and technology, Corvallis, Oregon State University, pp. $177-197$.

TERRY, C.S. (1985): “A Live Dog: Some Pointers on Translation", Undercurrent, 2, Tokyo Press, Ltd., pp. 1-12.

TOYAMA, S. (1977): "The Logic and Psychology of Japanese", Center News, vol. II, 2, Japanese Studies Center, The Japan Foundation, 3-4.

TOYAMA, S. (1988): "The Logic of Japanese", The Japan Times Weekly Overseas Edition, February 13, 8.

TOYOTA FOUNDATION (1986): Problems in Translation from Japanese to English in Literature and the Social Sciences and Implications for Retranslation Into Third Languages, prepared by EDS Inc., Editorial and Design Services, Tokyo.

URQUHART, A.H. (1984): "The Effect of Rhetorical Ordering on Readability", J.C. Alderson and A.H. Urquhart: Reading in a foreign language, Longman, London and New York, pp. 160-180.

WAKABAYASHI, J.F. (1990): "Some Stylistic Characteristics of Japanese and the Implications for JapaneseEnglish Translation", Proceedings of the First International Japanese-English Translation Conference, May 26-27, 1990, Hakone, Japan (forthcoming).

WALEY, A. (1958): "Notes on translation", The Atlantic Monthly, 202-5, pp. 107-112.

YANABU, A. (1983): Honyaku gakumon hihan: Nihongo no koozoo, honyaku no sekinin, Nihon honyakuka yoosei sentaa, Tokyo. 